\title{
Act In case of Depression: The evaluation of a care program to improve the detection and treatment of depression in nursing homes. Study Protocol
}

\author{
Debby L Gerritsen ${ }^{1 *}$, Martin Smalbrugge ${ }^{2}$, Steven Teerenstra ${ }^{3}$, Ruslan Leontjevas ${ }^{1}$, Eddy M Adang ${ }^{3}$,
} Myrra JFJ Vernooij-Dassen ${ }^{1,4,5}$, Els Derksen ${ }^{1}$ and Raymond TCM Koopmans ${ }^{1}$

\begin{abstract}
Background: The aim of this study is evaluating the (cost-) effectiveness of a multidisciplinary, evidence based care program to improve the management of depression in nursing home residents of somatic and dementia special care units. The care program is an evidence based standardization of the management of depression, including standardized use of measurement instruments and diagnostical methods, and protocolized psychosocial, psychological and pharmacological treatment.

Methods/Design: In a 19-month longitudinal controlled study using a stepped wedge design, 14 somatic and 14 dementia special care units will implement the care program. All residents who give informed consent on the participating units will be included. Primary outcomes are the frequency of depression on the units and quality of life of residents on the units. The effect of the care program will be estimated using multilevel regression analysis. Secondary outcomes include accuracy of depression-detection in usual care, prevalence of depression-diagnosis in the intervention group, and response to treatment of depressed residents. An economic evaluation from a health care perspective will also be carried out.
\end{abstract}

Discussion: The care program is expected to be effective in reducing the frequency of depression and in increasing the quality of life of residents. The study will further provide insight in the cost-effectiveness of the care program.

Trial registration: Netherlands Trial Register (NTR): NTR1477

\section{Background}

Depression is a common health problem in nursing home $(\mathrm{NH})$ residents: prevalence rates vary from 6 to even $50 \%$ [1-3]. Depression is strongly related to quality of life of NH residents [4], it seriously impacts wellbeing and daily functioning, and increases use of health care services and even mortality [5-7]. The association between depression and quality of life highlights the importance of identifying and treating depression in $\mathrm{NH}$ residents with and those without dementia $[8,4]$.

\footnotetext{
* Correspondence: d.gerritsen@elg.umcn.nl

'Department of Primary and Community Care, Center for Family Medicine, Geriatric Care and Public health, Radboud University Nijmegen Medical

Centre, the Netherlands

Full list of author information is available at the end of the article
}

Unfortunately, although depression is a treatable disorder [9], various studies have shown poor detection and undertreatment of depression in $\mathrm{NH}$ residents [2,10-12].

Several studies have demonstrated effects of pharmacological and psychosocial interventions for depression in nursing homes $[13,14]$. The review of Bharucha et al. [15] of 'talk therapies' for depression in long-term care presents evidence for an improvement in depressive symptoms after reminiscence/life review therapy. Moreover, there is evidence for the effectiveness of multifaceted interventions in residential care [16-18] and in nursing homes $[19,20]$.

The Nijmegen University NH Network (UKON), a collaboration between 12 care organizations and the 
Department of Primary and Community Care of the Radboud University Nijmegen Medical Centre, has developed the care program Act In case of Depression (AID), a multidisciplinary care program to identify and treat depression and monitor treatment effects. The care program is based on and in accordance with the recommendations as formulated in the Supplement Older Adults of the multidisciplinary evidence based guideline for diagnosis and treatment of depression [21] and the Consensus Statement of the American Geriatrics Society and the American Association of Geriatric Psychiatry [22]. The care program is an implementable plan of work that coordinates how the different disciplines should work together, fits in daily practice, and describes how new working methods are related to and can be integrated in the present care process following a step-by-step plan [23].

To date, cost effectiveness studies into the management of depression in $\mathrm{NH}$ have not been carried out, but are requested [24]. Gruber-Baldini et al. [10] did find increased involvement of mental health professionals in depressed long-term care residents with dementia, and Smalbrugge et al. [6] found that depressed residents of somatic units had increased use of medication, and received medical specialist consultation and treatment more often than non-depressed residents, implying expensive medical tests and hospital admissions. This paper describes a study that will evaluate the cost effectiveness of the care program AID.

\section{Methods/Design}

The study is a stepped wedge, multicentre intervention study on 14 somatic and 14 Dementia Special Care (DSC) units of UKON-NH.

A stepped wedge design is a type of crossover design in which different clusters (here: units) cross over from the control group to the intervention group at different time points. All clusters are measured at each time point. The first time point corresponds to a baseline measurement where none of the clusters receive the intervention of interest; at the last time point all clusters receive the intervention. After intermediate time points, clusters initiate the intervention. More than one cluster may start the intervention at a time point, but the time a cluster begins the intervention is randomized [25] (see Figure 1 for a graphical representation of the design). This way, comparisons within units ánd between units will be available, making the design very powerful. Another advantage of the design is that all involved units will receive the intervention - which is expected to increase motivation for participating in the study.

At the start of the data collection, the residents with informed consent of all 28 units are screened for depression (T0). Following this, each of the units is

\begin{tabular}{|c|c|c|c|c|c|c|c|}
\hline & Me & rel & & & & & \\
\hline & & TO & T1 & $\mathrm{T} 2$ & T3 & $\mathrm{T} 4$ & T5 \\
\hline & 1 & 0 & 1 & 1 & 1 & 1 & 1 \\
\hline 윽 & 2 & 0 & 0 & 1 & 1 & 1 & 1 \\
\hline 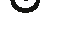 & 3 & 0 & 0 & 0 & 1 & 1 & 1 \\
\hline & 4 & 0 & 0 & 0 & 0 & 1 & 1 \\
\hline & 5 & 0 & 0 & 0 & 0 & 0 & 1 \\
\hline $\begin{array}{l}\text { Fig } \\
\text { desi } \\
\text { '1' re } \\
\text { imp }\end{array}$ & $\begin{array}{l}\text { re } \mathbf{1} \\
\text { yn. ' } 0 \text { ' } \\
\text { oresen } \\
\text { mente }\end{array}$ & $\begin{array}{l}\text { ents } \\
\text { asur } \\
\text { erve }\end{array}$ & $\begin{array}{l}\text { st af } \\
\text { i-cor }\end{array}$ & $\begin{array}{l}t \text { of } \\
\text { e in } \\
\text { in }\end{array}$ & $\begin{array}{l}\text { th } \\
\text { l car } \\
\text { entio }\end{array}$ & s be & $\begin{array}{l}\text { vedg } \\
\text { ditior }\end{array}$ \\
\hline
\end{tabular}

randomly assigned to one of 5 groups. Each group starts the intervention at different time points, directly after one of the measurements (T0-T4), which are each 4 months apart. In the four- month interval between T0 and T1, nursing staff of the first group is trained within the first month. After this month, the intervention runs for the subsequent 3 months in the first group before the second measurement (T1) of all 28 units takes place. After T1, the second group is trained, and the intervention starts in this group while it is continued in the first group. This procedure is repeated for the remaining 3 groups until, at the last measurement (T5), all 28 units are in the intervention condition. Consequently, the follow up in the intervention condition varies from 3 months for the last group, which starts with the intervention 1 month after T4, to 19 months for the first group, which starts after T0.

\section{Intervention}

Figure 2 shows the care program AID. AID proposes an evidence and practice based standardization of 5 components in the management of depression: 1) identification of depressive symptoms, 2) screening, 3) diagnosis, 4) treatment and 5) monitoring. AID includes standardized use of measurement instruments and diagnostical methods, and protocolized treatment that combines psychosocial, psychological and pharmacological interventions. Cooperation between the disciplines is prearranged. As the ability of nursing staff to detect depression can and should be enhanced [26], the multifaceted and multidisciplinary care program 'AID' starts with a training program for nursing staff on how to identify symptoms of depression using a short observation scale [27] and how to support $\mathrm{NH}$ residents with depressive symptoms or 


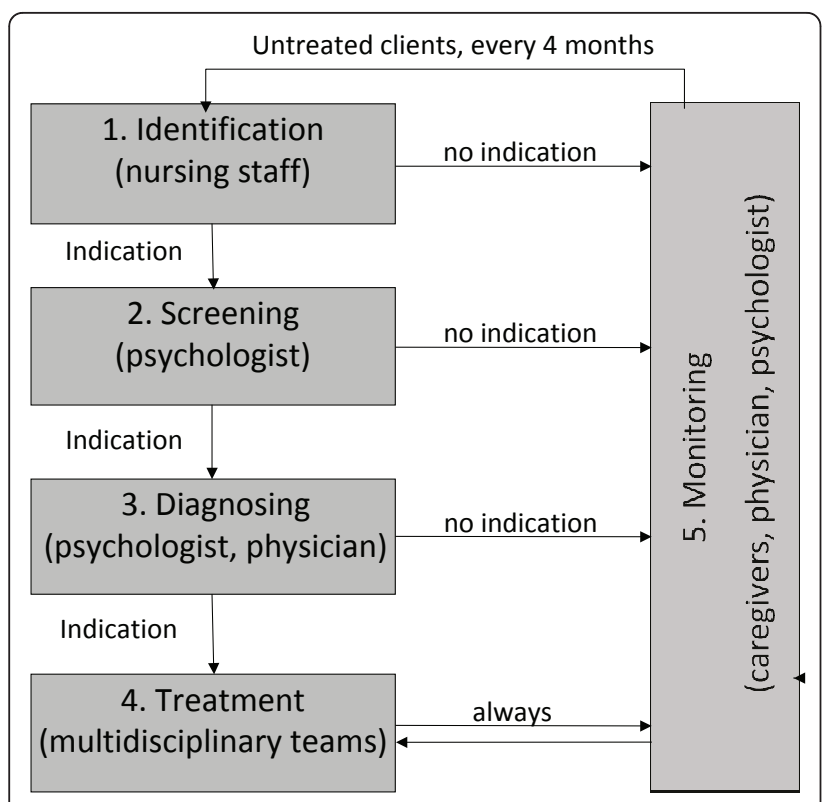

Figure 2 Graphical representation of the AID care program.

depression. Further, AID comprises plans of work for the identification, screening, diagnosing, treatment and monitoring of depression.

\section{Identification}

nursing staff completes a short observation scale for depression [27] for all participating residents on the unit. If according to the scores on the scale further screening is indicated, nursing staff contacts the psychologist who takes over the coordination on the screening and diagnosing. If no further screening is indicated, nursing staff will complete the observation scale again after 3-4 months.

\section{Screening}

The psychologist screens the 'identified' residents of somatic units for depressive symptoms with the GDS-8 (Geriatric Depression Scale-NH version; cut-off score 2/ 3) [28] and those of DSC units with the CSDD (Cornell Scale for Depression in Dementia; cut-off score 7/8) [29-31]. If screening with the GDS-8 in somatic residents is problematic because of cognitive or communication problems, the CSDD will also be administered [32].

For residents with depressive symptoms, i.e. total scores on the GDS- 8 or CSDD above the cut-off score, a diagnostic procedure will follow. For other residents, the identification phase will be repeated after 3-4 months.

\section{Diagnosing}

The elderly care physician and psychologist of each unit perform a diagnostic procedure including the use of chart information, caregiver interview, and examination of the resident (interview, physical examination). Diagnosis of major depression is established according to the DSM-IV-TR criteria. For minor depression the same criteria are used while only 2 to 4 symptoms are present $[33,34]$. In residents with dementia the Provisional Diagnostic Criteria for depression in Alzheimer's disease are applied (PDC) [35].

\section{Treatment}

Somatic and dementia residents with depressive symptoms, but without a clinical diagnosis of depression, are offered a personal day structure program made by the nursing staff in collaboration with the recreational therapist. Exercise and music therapy can be part of this day program. Psycho-education is also offered to the resident and/or relatives, including information about depressive symptoms and coping strategies.

Somatic residents with minor depression receive the same treatment as residents with depressive symptoms extended with individual life review therapy. This therapy is based on a protocol that has already been used successfully in Dutch residential care residents and is developed in close collaboration with the Dutch life review expert E. Bohlmeijer [36].

Somatic residents with major depressive disorder receive the same treatment as residents with minor depression extended with pharmacological treatment, when deemed appropriate by the elderly care physician. Prescription of pharmacological therapy is in accordance with the recommendations of the Supplement Older Adults [21].

For dementia residents with a PDC-depression diagno$\underline{\text { sis, }}$ treatment includes a personal day structure program, a behavioral management strategy developed by the psychologist and psycho education - especially of relatives. Apart from that, psychological treatment is offered: the clinical experts involved in the development of this care program agreed with recommendations made in the Supplement Older Adults [21] to intervene through the nursing staff (mediative therapy), but stressed that individual contact with the resident is also a necessity. Thus, for dementia residents, psychological treatment comprises of the psychologist supporting and supervising the nursing staff and recreational therapist more intensively in their execution of the day structure program and behavioral management strategy. This support takes place in a regular staff meeting, every two weeks. Within 1 month after the diagnosis, the day structure program and behavioral management strategy should be incorporated in regular care. The psychologist supervises the recreational therapist and nursing staff in at least 2 regular staff meetings. Additionally, if the depression in dementia residents is severe, pharmacological therapy can be given by the elderly care physician, when deemed appropriate.

\section{Monitoring}

Monitoring with a validated measurement instrument takes place to evaluate treatment. For this purpose, the 
GDS- 8 is used in somatic residents, and the CSDD is used in dementia residents.

\section{Sampling}

We calculated the sample-size using the following assumptions.

For somatic units: 25 residents per unit [37], a depression prevalence of $22 \%$ [38], a remission rate of $40 \%$ [39], and an attrition of $20 \%$ [38].

For DSC units: 20 residents per unit [40], a depression prevalence of $30 \%[10,40-42]$, a remission rate of $35 \%$ [13], and negligible attrition [40].

Based on these assumptions and a significance level alpha of 0.05 , a power of 0.80 and an ICC of 0.1 for both somatic and dementia residents, 14 clusters (units) with 6 measurements are needed in a stepped wedge design to allow multilevel analysis.

Given that the outcomes will be presented on unitlevel, during the data collection, newly admitted residents and/or their legal representatives are asked to provide informed consent on all units. This way, the sample size is not influenced by death or relocation of participating residents and can remain stable.

\section{Ethical approval}

The Medical Ethics Committee of the Radboud University Nijmegen Medical Centre (CMO Arnhem-Nijmegen) rated the study and pronounced that it is not burdensome for the participant. Each NH resident and/ or the legal representative on the participating units receives written and verbal information prior to the AID study and is only included in the study after having given written informed consent.

\section{Measurements}

Primary outcomes are frequency of depression and quality of life.

Frequency of depression (the percentage of residents with depression on a unit) is measured in somatic residents by a shortened version of the Geriatric Depression Scale (GDS) [43], the 8-item GDS-nursing home version (GDS-8) of Jongenelis et al. [28], which was made by deleting GDS-items that are not applicable to most $\mathrm{NH}$ residents. The GDS- 8 was validated in the AGED dataset, where it showed a good internal consistency of $\alpha=$ .80 and high sensitivity rates of $96.3 \%$ for major depression and $83.0 \%$ for minor depression, with a specificity rate of $71.7 \%$ at a cut-off score of 3 or more [28]. The GDS-8 also appears to be able to assess (change in) severity of depression [44]. The GDS-30 is originally a self-report instrument, the GDS-8 is interview based.

Frequency of depression in dementia residents is measured by the Cornell Scale for Depression in Dementia (CSDD)[29]. The CSDD is administered through interviewing nursing staff about their observations of the residents' behavior. The CSDD consists of 19 items each rated as $0=$ absent, $1=$ mild or intermittent and 2 = severe. The scores of the individual items are summed and a cut-off of 8 or more indicates depression [29]. Vida et al. [30] reported for a cut-off score of 8 or more, a sensitivity of $90 \%$ and specificity of $75 \%$ in residents with Alzheimer's Disease.

Quality of life in somatic residents is measured by the EQ-5D [45]. The EQ-5D instrument is a standardized non disease-specific instrument for describing and valuing Health Related Quality of Life [46]. There are two core components of the instrument: a description of the respondent's 'own health' using a health state classification system with five domains (mobility, self-care, usual activities, pain/discomfort and anxiety/depression) and a rating of 'own general health' by means of a visual analogue 'thermometer' scale. The EQ5D has shown a good validity and good test-retest reliability $[47,48]$.

In dementia residents quality of life is measured by the EQ-5D proxy version [49]. Thereto, nursing staff are asked to score the scale for the resident.

Secondary outcomes are percentage accuracy of depression-detection in usual care, prevalence of depression-diagnosis in the intervention group, and response to treatment of depressed residents.

Additional measurements involve measurement of cognitive functioning by the Mini Mental State Examination (MMSE) [50] and measurement of sociodemographic variables, mental health history - including prior depressive episodes-, present mental health condition including a dementia diagnosis -, possible treatment for depression, and somatic comorbidity.

Measurements are done by the research team. To study the compliance to the care program, the actual use of all components of the psychosocial, psychological and pharmacological treatment, as well as the factors determining this use, are registered. Accordingly, written checklists are used for nursing staff, recreational therapist, psychologist and elderly care physician, separately.

\section{Data-analysis}

Primary effects will be calculated using multilevel regression analysis, for somatic and DSC units separately. The GDS-8-scores and CSDD-scores will be used in the primary analysis. Age, sex, cultural background and cognitive status will be used as covariates. The EQ5D will be analyzed as another primary outcome in the intervention study. For cost analysis, see economic evaluation. A process analysis will be carried out to determine the actual use of the components of the psychosocial, psychological and pharmacological treatment, and to determine facilitators and obstacles.

Secondary outcomes (percentage accuracy of depressiondetection in usual care, prevalence of depression-diagnosis 
in the intervention group and response to treatment of depressed residents) will be analyzed using descriptive statistics.

\section{Economic evaluation}

This study investigates the efficiency of the care program AID compared to usual care as provided in $\mathrm{NH}$ units. If the program AID turns out to be successful, a decrease in the prevalence of depression in $\mathrm{NH}$ will occur. On the one hand the program needs investment in for example training of nursing staff and, consequently, generates extra costs compared to usual care. On the other hand it potentially generates savings as it reduces depression related time investment in $\mathrm{NH}$.

The economic evaluation is based on the general principles of a cost-effectiveness analysis from a healthcare viewpoint. Based on the above mentioned primary outcomes, two different incremental cost effectiveness ratios (ICERs) will be computed, answering the questions: 'How much money has to be invested additionally in the care program to gain one percentage point decrease in frequency of depression?' and 'How much money has to be invested additionally in the care program to gain one Quality-Adjusted Life Year (QALY)?'

The cost analysis consists of two main parts. First, on resident level, volumes of care (to determine the incremental direct health care costs) based on the production process of the care program and of depression decrease are measured prospectively using an activity based costing approach. Focusing on activities performed with costs accumulated at the activity level(s) of the health care production processes, standardized case report forms are used to assess time invested by nursing staff, psychologist, elderly care physician and recreational therapist. Also, number of hospital admissions (number of days in hospital) and use of antidepressant medication are recorded.

Second, the cost prices for each volume of consumption will be determined to use these for multiplying the volumes registered for each participating resident. The Dutch guidelines for cost analyses will be used [51]. For units of care/resources where no guideline or standard prices are available, real cost prices will be determined. Statistics of the total costs per resident will be determined for usual care and care according to the care program AID. Depending on the skewness of the parameter distributions, statistical testing of differences between strategies will be of a parametrical or non parametrical nature. The impact of deterministic variables, such as cost prices for volume parameters that are incremental cost drivers will be investigated using sensitivity analyses on the basis of the range of extremes.

The effect analysis adheres to the design of the study. Relevant for the economic evaluation are the frequency of depression (measured with GDS-8 and CSDD) and QALYs (utilities measured with the EQ-5D). Using the trapezium rule, the QALYs will be computed in order to perform a cost-effectiveness analysis comparing the two alternative strategies. Change in utilities (EQ-5D) will be based on the mean values for the residents when they are in the control condition and the mean values after having been in the intervention for 3 (all 5 groups), 7 (4 groups), 11 (3 groups), 15 (2 groups) and 19 months (1 group). ICERs will be computed and sampling uncertainty will be determined using the bootstrap or Fieller method. Finally, a cost-effectiveness acceptability curve will be derived that is able to evaluate efficiency by different thresholds for the ICERs.

\section{Discussion}

In this paper we described the design of a randomized trial to evaluate the (cost-)effectiveness of a multidisciplinary, evidence based care program to improve the management of depression in NH residents of somatic and DSC units. This study holds several unique elements.

First of all, the Department of Primary and Community Medicine of the Radboud University Nijmegen Medical Centre has established a structural collaboration with 12 care organizations (representing $40 \mathrm{NH}$ and 100 residential homes) in the Nijmegen University NH Network (UKON). An expert group of the UKON has developed the care program AID, based on evidence based guidelines and the Consensus Statements [21,22]. Implementation is expected to be successful, because it fits with daily practice and describes how new working methods are related to and can be integrated in the present care process following a step-by-step plan [23].

Secondly, the intervention is based on a stepped care approach: the more serious the depressive complaints or the depression, the more intense the intervention will be. The standardized interventions will be tailored to the needs of the individual resident. This will expectedly increase its effectiveness and facilitate transferring this strategy to other nursing homes.

Finally, the design of the study -the stepped wedge design- is a relatively new design, and has not been applied before in long term care. Using a stepped wedge design signifies that all participating units will crossover from the control condition to the intervention condition during the study. This is expected to increase the motivation of $\mathrm{NH}$ workers to participate in scientific research.

In conclusion, the care program is expected to be effective in reducing the frequency of depression and in increasing the quality of life of residents. The study also will provide insight in the program's cost- effectiveness.

Acknowledgements and Funding

This study was funded by the Netherlands Organisation for Health Research and Development (ZonMw). 


\section{Author details}

'Department of Primary and Community Care, Center for Family Medicine, Geriatric Care and Public health, Radboud University Nijmegen Medical Centre, the Netherlands. ${ }^{2}$ Department of Nursing Home Medicine, EMGO Institute for Health and Care Research, VU University Medical Center, Amsterdam, the Netherlands. ${ }^{3}$ Department of Epidemiology, Biostatistics, and HTA, Radboud University Nijmegen Medical Centre, the Netherlands. ${ }^{4}$ Scientific Institute for Quality of Healthcare, Radboud University Nijmegen Medical Centre, the Netherlands. ${ }^{5}$ Kalorama Foundation, Beek-Ubbergen, the Netherlands.

\section{Authors' contributions}

DLG designed the study and the intervention, and wrote the paper. MS designed the study and the intervention, and co-wrote the paper. ST introduced and planned the stepped wedge design of the study. RL COdesigned the intervention and co-wrote the paper. EA designed the economic evaluation of the study. MVD assisted in the design of the study and co-wrote the paper. ED assisted in the design of the study and the intervention and co-wrote the paper. RK assisted in the design of the study and co-wrote the paper. All authors read and approved this manuscript.

\section{Competing interests}

The authors declare that they have no competing interests.

Received: 13 April 2011 Accepted: 20 May 2011 Published: 20 May 2011

\section{References}

1. Jongenelis K, Pot AM, Eisses AM, Beekman AT, Kluiter H, van Tilburg W, Ribbe MW: Depression among older nursing home patients: A review. Tijdschr Gerontol Geriatr 2003, 34:52-59.

2. Kramer D, Allgaier AK, Fejtkova S, Mergl R, Hegerl U: Depression in nursing homes: prevalence, recognition, and treatment. Int J Psychiatry Med 2009, 39:345-358.

3. Snowdon J, Rosengren D, Daniel F, Suyasa L: Australia's use of the Cornell scale to screen for depression in nursing homes. Australas J Ageing 2011, 30:33-36.

4. Hoe J, Hancock G, Livingston G, Orrell M: Quality of life of people with dementia in residential care homes. Br J Psychiatry 2006, 188:460-464.

5. Demyttenaere K, Hemels MEH, Hudry J, Annemans L: A cost-effictiveness model of Escitalopram, Citalopram and Venlafaxine as first-line treatment for major depressive disorder in Belgium. Clin Therapeutics 2005, 27:111-124.

6. Smalbrugge M, Pot AM, Jongenelis $K$, Gundy CM, Beekman AT, Eefsting JA: The impact of depression and anxiety on well being, disability and use of health care services in nursing home patients. Int J Geriatr Psychiatry 2006, 21:325-332.

7. Beekman ATF, Deeg DJH, Braam AW, Smit JH, van Tilburg W: Consequences of major and minor depression in later life: a study of disability, well-being and service utilization. Psychol Med 1997, 27:1397-1409.

8. Selwood A, Thorgrimsen L, Orrell M: Quality of life in dementia-a oneyear follow-up study. Int I Geriatr Psychiatry 2005, 20:232-237.

9. Rovner BW: Depression and increased risk of mortality in the nursing home patient. Am J Med 1993, 94(suppl5A):19S-23S.

10. Gruber-Baldini AL, Zimmerman S, Boustani M, Watson LC, Williams CS, Reed PS: Characteristics associated with depression in long-term care residents with dementia. Gerontologist 2005, 45S11:50-55.

11. Jongenelis K: Depression in Dutch nursing homes: The Amsterdam Groningen Elderly Depression Study. PhD Thesis2006 VU University Medical Center.

12. Ayalon $\mathrm{L}$, Arean $\mathrm{P}$, Bornfeld $\mathrm{H}$ : Correlates of knowledge and beliefs about depression among long-term care staff. Int I Geriatr Psychiatry 2008, 23:356-363.

13. Snowden M, Sato K, Roy-Byrne P: Assessment and treatment of nursing home residents with depression or behavioral symptoms associated with dementia: a review of the literature. J Am Geriatr Soc 2003, 51:1305-1317

14. Peskind ER: Management of depression in long-term care of patients with Alzheimer's disease. J Am Med Dir Assoc 2003, 4:S141-145.

15. Bharucha AJ, Dew MA, Miller MD, Borson S, Reynolds C: Psychotherapy in long-term care: a review. J Am Med Dir Assoc 2006, 7:568-580.
16. Llewellyn-Jones RH, Baikie KA, Smithers H, Cohen J, Snowdon J, Tennant CC: Multifaceted shared care intervention for late life depression in residential care: randomised controlled trial. BMJ 1999, 319:676-682.

17. Lewellyn-Jones RH, Baikie KA, Smithers H, Cohen J, Snowdon J, Tennant CC: How to help depressedolder people living in residential care: a multifaceted shared-care intervention for late-life depression. Int Psychogeriatr 2001, 13:477-492.

18. Cuijpers $P$, van Lammeren P: Secondary prevention of depressive symptoms in elderly inhabitants of residential homes. Int J Geriatr Psychiatry 2001, 16:702-708.

19. Llewellyn-Jones RH, Snowdon J: Depression in nursing homes: ensuring adequate treatment. CNS Drugs 2007, 21:627-640.

20. Brooker DJ, Woolley RJ, Lee D: Enriching opportunities for people living with dementia in nursing homes: An evaluation of a multi-level activitybased model of care. Aging \& Mental Health 2007, 11:361-370.

21. Kok R: Multidisciplinaire richtlijn depressie, addendum ouderen Utrecht: CBO/ Trimbosinstituut; 2008

22. American Geriatrics Society \& American Association for Geriatric Psychiatry: Consensus statement on improving the quality of mental health care in US nursing homes: management of depression and behavioural symptoms associated with dementia. J Am Geriatr Soc 2003, 51:1287-1298.

23. Grol RP, Wensing M: Implementatie: Effectieve verbetering van de patiëntenzorg Amsterdam: Elsevier gezondheidszorg; 2010.

24. Lyne KJ, Barrett P, Evans C, Barkham M: Dimensions of variation on the CORE-OM. Br J Clin Psychol 2006, 45(Pt 2):185-203.

25. Hussey M, Hughes JP: Design and analysis of stepped wedge cluster randomized trials. Contemporary Clinical Trials 2007, 28:182-191.

26. Eisses AM, Kluiter $\mathrm{H}$, Jongenelis $\mathrm{K}$, Pot AM, Beekman AT, Ormel J: Care staff training in detection of depression in residential homes for the elderly: randomised trial. Br J Psychiatry 2005, 186:404-409.

27. Hammond MF, O'Keeffe ST, Barer DH: Development and validation of a brief observer-rated screening scale for depression in elderly medical patients. Age Ageing 2000, 29:511-515.

28. Jongenelis K, Gerritsen DL, Pot AM, Beekman AT, Eisses AM, Kluiter H, Ribbe MW: Construction and validation of a patient and user-friendly nursing home version of the Geriatric Depression Scale. Int J Geriatr Psychiatry 2007, 22:837-842.

29. Alexopoulos GS, Abrams RC, Young RC, Shamoian CA: Cornell Scale for Depression in Dementia. Biol Psychiatry 1988, 23:271-284.

30. Vida S, Des Rosiers P, Carrier L, Gauthier S: Depression in Alzheimer's disease: receiver operating characteristic analysis of the Cornell Scale for Depression in Dementia and the Hamilton Depression Scale. J Geriatr Psychiatry Neurol 1994, 7:159-162.

31. Kørner A, Lauritzen L, Abelskov K, Gulmann N, Brodersen AM, WedervangJensen T, Kjeldgaard KM: The Geriatric Depression Scale and the Cornell Scale for Depression in Dementia: A validity study. Nord J Psychiatry 2006, 60:360-364.

32. UVNN, Nieuwboer M, Derksen E: Meetschalen stemming in het verpleeghuis: verslag van consensustraject stemming Nijmegen; 2007.

33. American Psychiatric Association: Diagnostic and Statistical Manual of Mental Disorders, Fourth Edition, Text Revision Washington DC; 2000.

34. Koopmans RT, Lavrijsen JC, Hoek JF, Went PB, Schols JM: Dutch elderly care physician: a new generation of nursing home physician specialists. J Am Geriatr Soc 2010, 58:1807-1809.

35. Olin JT, Katz IR, Meyers BS, Schneider LS, Lebowitz BD: Provisional diagnostic criteria for depression of Alzheimer disease: rationale and background. Am J Geriatr Psychiatry 2002, 10:129-141.

36. Bohlmeijer $E$, Roemer M, Cuijpers P, Smit F: The effects of reminiscence on psychological well-being in older adults: A meta-analysis. Aging Mental Health 2007, 11:291-300.

37. UVNN, Nieuwboer M, Derksen E: Inventarisatie meetschalen Nijmegen; 2005

38. Jongenelis K, Pot AM, Eisses AM, Beekman AT, Kluiter H, Ribbe MW: Prevalence and risk indicators of depression in elderly nursing home patients: the AGED study. J Affect Disord 2004, 83:135-142

39. Kok RM, Nolen WA, Heeren TJ: Venlafaxine versus nortriptyline in the treatment of elderly depressed inpatients. Int J Geriatr Psychiatry 2007, 22:1247-1254

40. Zuidema SU, Derksen E, Verhey FR, Koopmans RT: Prevalence of neuropsychiatric symptoms in a large sample of Dutch nursing home patients with dementia. Int J Geriatr Psychiatry 2007, 22:632-638. 
41. Evers MM, Samuels SC, Lantz M, Khan K, Brickman AM, Marin DB: The prevalence, diagnosis and treatment of depression in dementia patients in chronic care facilities in the last six months of life. Int I Geriatr Psychiatry 2002, 17:464-472.

42. Verkaik R, Francke AL, van Meijel B, Ribbe MW, Bensing JM: Comorbid depression in dementia on psychogeriatric nursing home wards: which symptoms are prominent? Am J Geriatr Psychiatry 2009, 17:565-573.

43. Yesavage JA, Brink TL, Rose T, Lum O, Huang V, Adey M, Leirer V: Development and validation of a geriatric screening scale: a preliminary report. J Psychiatr Res 1983, 17:37-49.

44. Smalbrugge $M$, Jongenelis $K$, Pot AM, Beekman AT, Eefsting JA: Screening for depression and assessing change in severity of depression is the Geriatric Depression Scale (30-, 15- and 8-item version) useful for both purposes in nursing home patients? Aging Mental Health 2008, 12:244-248.

45. Group EuroQol: EuroQol - a new facility for the measurement of healthrelated quality of life. Health Policy 1999, 5:21-32.

46. Lamers LM, Stalmeier PFM, McDonnell J, Krabbe PFM, Busschbach van JJ: Kwaliteit van leven meten in economische evaluaties: Het Nederlandse EQ-5D tarief. Nederlands Tijdschrift voor de Geneeskunde 2005, 149:1574-1578.

47. Agt van HME, Essink-Bot ML, Krabbe PFM, Bonsel GJ: Test-retest reliability of health state valuations collected with the EuroQol questionnaire. Social Science \& Medicine 1994, 45:1537-1544.

48. Coast J, Peters TJ, Richards SH, Gunnell DJ: Use of the EuroQoL among elderly acute care patients. Quality of Life Research 1998, 7:1-10.

49. Jönsson $L$, Andreasen $N$, Kilander I, Soininen $H$, Waldemar $G$, Nygaard $H$, Winblad B, Jönhagen ME, Hallikainen M, Wimo A: Patient- and proxyreported utility in Alzheimer disease using the EuroQoL. Alzheimer Dis Assoc Disord 2006, 20:49-55.

50. Folstein MF, Folstein SE, McHugh PR: Mini mental state: A practical method for grading the cognitive state of patients for the clinician. Journal of Psychiatric Research 1975, 12:189-198.

51. Oostenbrink JB: Handleiding voor kostenonderzoek: methoden en richtlijnprijzen voor economische evaluaties in de gezondheidszorg Diemen: CVZ; 2004.

\section{Pre-publication history}

The pre-publication history for this paper can be accessed here: http://www.biomedcentral.com/1471-244X/11/91/prepub

doi:10.1186/1471-244X-11-91

Cite this article as: Gerritsen et al:: Act In case of Depression: The evaluation of a care program to improve the detection and treatment of depression in nursing homes. Study Protocol. BMC Psychiatry 2011 11:91.

\section{Submit your next manuscript to BioMed Central and take full advantage of:}

- Convenient online submission

- Thorough peer review

- No space constraints or color figure charges

- Immediate publication on acceptance

- Inclusion in PubMed, CAS, Scopus and Google Scholar

- Research which is freely available for redistribution 